\title{
Optimization of tocols and $\gamma$-oryzanol extraction from rice bran using ultrasound and soybean oil as a green solvent
}

\author{
${ }^{1}$ Loypimai, P., ${ }^{2}$ Moongngarm, A., ${ }^{1}$ Sittisuanjik, A. and ${ }^{1}$ Khamanan, S. \\ ${ }^{1}$ Division of Food Science and Technology, Faculty of Science and Technology, Bansomdejchaopraya \\ Rajabhat University, Bangkok 10600, Thailand \\ ${ }^{2}$ Department of Food Technology and Nutrition, Faculty of Technology, Mahasarakham University, \\ Mahasarakham 44150, Thailand
}

\author{
Article history: \\ Received: 15 July 2020 \\ Received in revised form: 31 \\ August 2020 \\ Accepted: 31 October 2020 \\ Available Online: 8 \\ November 2020 \\ Keywords: \\ $\gamma$-oryzanol, \\ Response surface \\ methodology, \\ Ultrasound, \\ Soybean oil
}

DOI:

https://doi.org/10.26656/fr.2017.4(6).360

\begin{abstract}
A new process was developed to extract tocols and $\gamma$-oryzanol from rice bran using ultrasound with soybean oil as a natural solvent. Results were compared to the conventional solvent method. The extraction process was optimized using response surface methodology (RSM) with three independent process variables as amplitude level (A) (20-60\%), extraction temperature (B) $\left(25-65^{\circ} \mathrm{C}\right)$ and time (C) (20-60 mins). Statistical analysis indicated that models developed for all responses were significant. Linear terms of all process variables had significant effects on $\alpha$-tocopherol, $\gamma$-tocopherol, and $\gamma$ oryzanol, while quadratic effects of amplitude level $\left(\mathrm{A}^{2}\right)$, temperature $\left(\mathrm{B}^{2}\right)$ and time $\left(\mathrm{C}^{2}\right)$ on all responses were highly significant. Optimal process conditions for maximum yield of tocopherols and $\gamma$-oryzanol were $40 \%$ amplitude level, $65^{\circ} \mathrm{C}$ solution temperature and 40 mins. Yields of $\alpha$-tocopherol and $\gamma$-oryzanol in oil extracted under the optimal conditions or ultrasound-assisted soybean oil extraction (O-UASO) were comparable to oil yield produced by conventional solvent extraction (O-CSE). Interestingly, O-UASO showed higher total antioxidant activities compared with O-CSE. Extraction using ultrasound with soybean oil was proposed as an effective alternative green process to improve oil functionality without the need for separating environmentally hazardous organic solvents.
\end{abstract}

\section{Introduction}

Rice (Oryza sativa L.) is a staple food crop for more than half of the global population and is consumed by over $90 \%$ of people in Asia, especially Southeast Asia (Thailand), China, and India (FAO, 2016). Before consumption or serving as an ingredient in food products, rice is generally milled and/or polished and 8$10 \%$ of the outer grain layer is removed as rice bran (Loypimai et al., 2009). Previous studies (Loypimai et al., 2009; Loypimai et al., 2015) reported that the rice bran fraction contained highly valuable bioactive components such as tocols (tocopherols and tocotrienols), $\gamma$-oryzanol and phenolic compounds. These compounds are now generating interest because of their potential beneficial effects on human health and improving food storage stability. Nevertheless, a large amount of rice bran is not efficiently utilized and is mainly used as a feedstock instead of realizing its potential as a functional food ingredient and as a productive source of healthy rice bran oil.
Traditionally, conventional extraction methods with organic solvents such as methanol and hexane have been used to recover these valuable compounds from rice bran (Loypimai et al., 2009; Loypimai et al., 2016). Currently, the use of these solvents in the food industry presents some disadvantages including their flammable, volatile, and toxic nature, and subsequent environmental pollution (Balachandran et al., 2008). Therefore, safer extraction methods with improved environmental and economic aspects have recently gained interest in the food industry (Chemat et al., 2012). Extraction using edible vegetable oils is a green process to produce natural products, while environmentally friendly solvents reduce energy consumption and produce non-denatured extract without contaminants (Chemat et al., 2012). In addition, the oil is used as a barrier to prevent the attraction of oxygen molecules and, consequently, retard oxidation and degradation rates of the carotenoid extracts (Pu et al., 2010). However, high oil viscosity is a major problem which results in low diffusivity and low 
extraction yield. A green extraction method that offers high product yield and concentration of value-added compounds such as bioactive substances needs to be developed.

Recently, ultrasound technology has become a popular extraction method in the food industry with low process time, allowing reduction of solvents and resulting in higher quality products and extraction yields. Ultrasound has been successfully applied to extract different types of compounds from natural products such as antioxidants (Virot et al., 2010) rice bran oil (Khoei and Chekin, 2016), phenolic compounds (Chen et al., 2015), green absolute from thyme using sunflower oil as a solvent (Mnayer et al., 2017) and carotenoids from pomegranate wastes using vegetable oils (Goula et al., 2017). Mechanical and cavitation processes occur at the contact surface between the food matrix and liquid solvent phase when ultrasound is applied, resulting in rupture of the cell walls, particle size reduction, and enhanced mass transfer across the cell membrane and, consequently, increased recovery yield of bioactive compounds and other extractable substances (Pan et al., 2011; Goula et al., 2017; Mnayer et al., 2017).

To the best of our knowledge, no reports have been published regarding the extraction of bioactive compounds, especially the lipophilic group, from rice bran using ultrasound techniques with soybean oil. Here, we developed a new extraction approach for tocols and $\gamma$ -oryzanol from rice bran using ultrasound, using soybean oil as a substitute for organic solvents in line with green extraction concepts. Our developed extraction process for tocols and $\gamma$-oryzanol was optimized using response surface methodology (RSM). Yields of tocols and $\gamma$ oryzanol in the oil as well as antioxidant activity obtained from the optimal conditions were compared with the conventional solvent extraction process.

\section{Materials and methods}

\subsection{Materials}

Rice bran (Oryza sativa L.) as a by-product of rice milling process was supported by a local farmer $(8 \pm 1.0 \%$ degree of milling) in Nakhon Ratchasima Province, Thailand. After milling, the fresh bran obtained was passed through a $750 \mu \mathrm{m}$ mesh sieve to separate the foreign materials. Before extraction, the bran was stabilized following the method described by Loypimai et al. (2009), and $180 \mathrm{~g}$ was then heated in an autoclave (ACV-3167 IWAKI) at $115^{\circ} \mathrm{C}$. The inside temperature of the sample was raised to $105^{\circ} \mathrm{C}$, held there for $1 \mathrm{~min}$, then removed from the chamber and cooled to ambient temperature.
Refined soybean oil as an environmentally friendly solvent was obtained from a local supermarket (Bangkok, Thailand). Before experimentation, the tocols and $\gamma$-oryzanol in the soybean oil and raw rice bran sample were identified and quantified.

\subsection{Extraction procedures}

\subsubsection{Preparation of oil produced by ultrasound-} assisted soybean oil extraction (O-UASO)

Ultrasonication was applied to assist soybean oil extraction of tocols and $\gamma$-oryzanol from rice bran. The procedure (Figure 1-b) was carried out following the method of Goula et al. (2017) with slight modifications. In short, approximately $40 \mathrm{~g}$ of the stabilized bran sample was added to a beaker containing $200 \mathrm{~mL}$ of soybean oil. The mixture was then subjected to ultrasonic radiation using an ultrasound (VCX 500 Vibra -CellTM, Sonics and Materials Inc., USA) equipped with an ultrasonic probe. During the extraction process, the solution temperature in pulse mode was measured continuously using a probe controller. Operating variables were adjusted as follows: different levels of amplitude at the probe $(20,40$, and $60 \%)$; extraction time interval (20, 40 and 60 mins); temperature range (25, 45 and $65^{\circ} \mathrm{C}$ ). Here, the ultrasonic device used was a titanium alloy microprobe with $13 \mathrm{~mm}$ tip diameter (length $136 \mathrm{~mm}$, weight $340 \mathrm{~g}$ ) (Model CV334, USA), operated at maximum frequency and power of $20 \mathrm{kHz}$ and $500 \mathrm{~W}$, respectively. After ultrasonic pretreatment, each slurry sample was filtered through a vacuum pump (Buchi, Switzerland) using a filter paper (Whatman No. 4) before centrifuging at $6,000 \times g$ for 10 mins to obtain the oil extract. All experiments were performed in triplicate.

\subsubsection{Preparation of oil produced by conventional solvent extraction (O-CSE)}

Conventional solvent extraction (Figure 1-a) to prepare oil enriched with rice bran tocols and $\gamma$-oryzanol was carried out following the procedure described by Moongngarm et al. (2019). The tocols and $\gamma$-oryzanol concentrate extract obtained was then added into the soybean oil, blended using a homogenizer (KIA T25 Ultra Turrax, Germany) to obtain oil enriched with rice bran tocols and $\gamma$-oryzanol, and served as the control sample or O-CSE (Goula et al., 2017).

\subsection{HPLC analysis for tocopherols and $\gamma$-oryzanol}

Contents of tocopherols ( $\alpha$-tocopherol, $\delta$-tocopherol, and $\gamma$-tocopherol) and $\gamma$-oryzanol in the solvent (soybean oil), raw rice bran and oil extract obtained from different extraction processes were determined using an HPLC equipped with a Prominence Diode Array (PDA) 


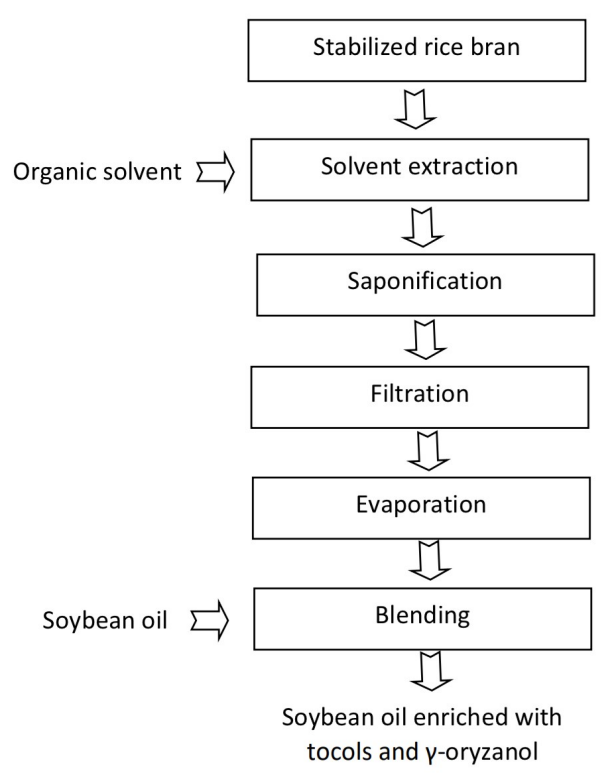

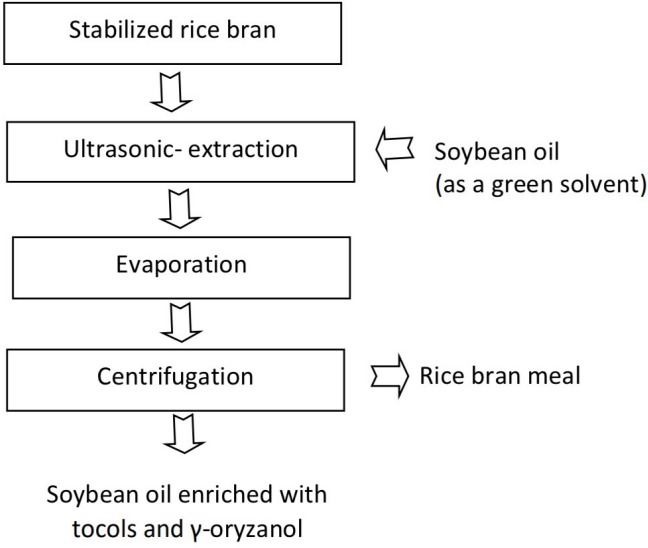

(b)

(a)

Figure 1. Extraction process of tocols and $\gamma$-oryzanol from rice bran using (a) conventional solvent extraction, and (b) ultrasound -assisted extraction using soybean oil as a green solvent.

detector according to the method of Loypimai et al. (2009) with slight modifications. Each oil extract sample $(0.5 \mathrm{~g})$ was added to $5.0 \mathrm{~mL}$ of $\mathrm{n}$-hexane and mixed using a vortex mixer for $1 \mathrm{~min}$ for homogeneous dissolution. The mixture was then passed through a 0.45 $\mu \mathrm{m}$ micropore filter membrane (Whatman, USA) prior to injection. Separations were carried out at $45^{\circ} \mathrm{C}$ using a C18 analytical column (Phenomenex $4 \mu \mathrm{m}, \mathrm{C} 18$, $150 \times 4.6 \mathrm{~mm}$ ) equipped with a security guard column (Phenomenex $4 \mu \mathrm{m}, \mathrm{C} 18,50 \times 4.6 \mathrm{~mm}$ ) and a mobile phase consisting 92\% methanol in deionized water (solvent A) and n-butanol (solvent B) at a flow rate of $1.0 \mathrm{~mL} / \mathrm{min}$. Gradient elution applied was: 0-12 mins, 3$5 \% \mathrm{~B}$; and $12-25 \mathrm{mins}, 5-3 \% \mathrm{~B}$. Total gradient time of the analysis including washing and reconditioning of the column was 25 mins. Retention times and the total peak area of standard tocols (Sigma-Aldrich Chemical Co., St. Louis, MO, USA) at $292 \mathrm{~nm}$ and standard $\gamma$-oryzanol (Tsuno Food Industrial Co., Ltd., Wakayama, Japan) at $325 \mathrm{~nm}$ were used to identify and quantify each compound in the test sample and concentrations were calculated as follows:

Tocols or $\gamma$-oryzanol $(\mu / \mathrm{g})$ increase $=$ Content in the oil extract - Content in the soybean oil (solvent)

\subsection{Experimental design and optimization}

A central composite design (CCD) was used to investigate the effect and relevance of the operating parameters during ultrasonic-assisted solvent (soybean oil) extraction of tocols and $\gamma$-oryzanol from rice bran. Three independent factors as amplitude level (\%), extraction time (min) and temperature $\left({ }^{\circ} \mathrm{C}\right)$ were evaluated, as well as the interaction between these variables. Low and high levels of constraints in the actual (uncoded) form were taken as $20-60 \%$ for amplitude level, 20-60 mins for extraction duration and $25-65^{\circ} \mathrm{C}$ for extraction temperature. Limiting values of each variable range were selected on the basis of data obtained from preliminary experiments and regulation limitations in the ultrasonic apparatus. Three different levels for each experiment in coded form were $-1,0$ and +1 as listed in Table 1. Three functions were assumed to exist between each response and the input factors. A second-order polynomial equation was used to fit the experimental data of the studied variables. The generalized second-order polynomial model used in the response surface analysis is given below:

$$
Y_{k}=B_{k 0}+\sum_{i=1}^{3} B_{k i} x_{i}+\sum_{i=1}^{3} B_{k i i} x_{i}^{2}+\sum_{i=1}^{3} B_{k i j} x_{i} x_{j}+e k
$$

where $Y_{k}=$ response variable $\left(Y_{1}=\alpha\right.$-tocopherol; $Y_{2}=\delta$ -tocopherol; $\mathrm{Y}_{3}=\gamma$-tocopherol; $\mathrm{Y}_{4}=\gamma$-oryzanol) and $\mathrm{x}_{\mathrm{i}}$ represents the coded independent variables $(i=1,2,3$ representing $\mathrm{A}, \mathrm{B}$, and $\mathrm{C}$ respectively, where $\mathrm{A}=$ amplitude level (\%); $\mathrm{B}=$ extraction time ( $\mathrm{min}) ; \mathrm{C}=$ extraction temperature $\left.\left({ }^{\circ} \mathrm{C}\right)\right)$. $\mathrm{B}_{\mathrm{k} 0}$ is the value of the fitted

Table 1. Uncoded and coded independent variables used in response surface methodology (RSM) design for optimization studies

\begin{tabular}{lcccccc}
\hline Independent variable & Coded level & -1.628 & -1 & 0 & 1 & 1.628 \\
\hline Amplitude level $(\%)$ & $\mathrm{A}$ & 6.36 & 20 & 40 & 60 & 73.64 \\
Extraction temperature $\left({ }^{\circ} \mathrm{C}\right)$ & $\mathrm{B}$ & 11.36 & 25 & 45 & 65 & 78.64 \\
Extraction time (min) & $\mathrm{C}$ & 6.36 & 20 & 40 & 60 & 73.64 \\
\hline
\end{tabular}


response at the center point of the design and $\mathrm{B}_{\mathrm{ki}}, \mathrm{B}_{\mathrm{kii}}$, and $\mathrm{B}_{\mathrm{kij}}$ are the linear, quadratic and interaction regression coefficients, respectively.

A CCD with three independent variables at three levels was used to study the response patterns and optimal combinations of variables. RSM was applied to create models, design experiments, search for optimal conditions and evaluate the effects of factors using the statistical package Design-expert ${ }^{\circledR}$ version 7.1.5 (StatEase Inc., USA). Experiments involved a total of eighteen runs with four replications at the center point to decrease experimental error and avoid the effects of extraneous variables. Statistical significance of the terms in the regression equation was examined by analysis of variance (ANOVA). Three-dimensional models were generated as response surface plots for the different variables while maintaining the value of the third variable as constant (at the central value). Response surface plots showed accurate geometrical representation and provided useful information about the behavioral systems in the experimental design. The models obtained were used to interpret the effect of various variables on the responses (tocols and $\gamma$-oryzanol). Optimization of the extraction process aimed to determine the levels of the three independent variables, namely (amplitude level, extraction time and temperature) which gave maximum possible tocols and $\gamma$-oryzanol.

\subsection{Antioxidant activity analysis}

The oil products obtained from the optimal conditions of UASO and CSE were dissolved with the mixture solvents (methanol: hexane, $3: 2$ ) before analysis following the method developed by Loypimai et al. (2015) with slight modifications. Briefly, $1.0 \mathrm{~g}$ of the sample was dissolved in $5 \mathrm{~mL}$ of mixture solvents by placing the mixture on a sonicator (Vibra-Cell ${ }^{\mathrm{TM}}, 130 \mathrm{~W}$, $20 \mathrm{kHz}$ ) for $5 \mathrm{mins}$, followed by evaporating in a rotary evaporator to remove the solvent. The residue was then dissolved in $2 \mathrm{~mL}$ of methanol and stored at $-20^{\circ} \mathrm{C}$. Each extract was analyzed for their antioxidant activity by three different chemical assays based on diverse food system mechanisms. The solvent (soybean oil) used was determined to compare with the oil extract obtaining the optimal extraction condition.

\subsubsection{Diphenyl-2-picrylhydrazyl (DPPH) assay}

DPPH radical-scavenging activity was evaluated using a UV-Vis Spectrophotometer (G10S UV-Vis model, Thermo Fisher Scientific, China) and calculated as the value of the sample concentration providing $50 \%$ of inhibition activity $\left(\mathrm{IC}_{50}\right)$ (Dasgupta and De, 2004).

\subsubsection{Ferric reducing antioxidant power (FRAP) assay}

Reducing power of the extract was determined on the basis of the capacity to convert $\mathrm{Fe}^{3+}$-TPTZ to a blue colored $\mathrm{Fe}^{2+}$-TPTZ (Benzie and Strain, 1996). The absorbance was then measured at $539 \mathrm{~nm}$ and results were expressed in $\mu \mathrm{mol} \mathrm{FeSO}_{4}$ equivalent/g sample.

\subsubsection{Total antioxidant capacity assay}

Total antioxidant capacity (TAC) assay was determined using the method documented by Dasgupta and De (2004). Antioxidant activity was expressed as the number of standard synthetic gallic acid equivalents.

\subsection{Statistical analysis}

Response surface methodology was applied to optimize the experimental data using Design-Expert (version 7.1.5, Stat-Ease Inc., USA). A polynomial equation was fitted to the data to obtain a regression equation. All experiments and analyses were carried out in triplicate. Comparisons of increased tocols and $\gamma$ oryzanol content and antioxidant activity in oils produced from different extraction processes were subjected to one-way analysis of variance (ANOVA). Significant differences between treatments were determined by Duncan's Multiple Range Test. A $p$-value less than 0.05 was declared statistically significant.

\section{Results and discussion}

\subsection{Tocols and $\gamma$-oryzanol content in soybean oil}

According to our preliminary study, extraction using soybean and sunflower oils exhibited higher rice bran tocols and $\gamma$-oryzanol content in the oil extract compared with oil extracted by other edible vegetable oil (coconut, canola, corn and palm oil) solvents. Based on this and low cost, soybean oil was considered as the optimal solvent. Soybean oil combined with ultrasound was used to extract tocols and $\gamma$-oryzanol from rice bran by focusing on process optimization using response surface methodology (RSM) with three independent process variables. Before the experiment, characteristics of the solvent as soybean oil, in terms of amounts of tocols and $\gamma$-oryzanol, were determined (data not shown). Three isomers of tocopherol including $\alpha$-tocopherol $(71.12 \pm 5.61 \mu \mathrm{g} / \mathrm{g}), \gamma$-tocopherol $(37.12 \pm 5.61 \mu \mathrm{g} / \mathrm{g})$, and $\delta$-tocopherol $(123.5 \pm 11.3 \mu \mathrm{g} / \mathrm{g})$ were found. Results concurred with Grilo et al. (2014) who reported that $\alpha$ tocopherol and $\gamma$-tocopherol were observed in commercial soybean oils at average concentrations of $71.3 \pm 6.4 \mu \mathrm{g} / \mathrm{g}$ and $273.3 \pm 11.1 \mu \mathrm{g} / \mathrm{g}$, respectively. As expected, $\gamma$-oryzanol as a unique and important phytochemical which is almost always distributed in rice 
grains, and especially in the rice bran fraction, was not detectable in the soybean oil. Several previous studies (Loypimai et al., 2009; Zhang et al., 2013; Loypimai et al., 2015) reported a high concentration of $\gamma$-oryzanol in rice bran and rice bran oil ranging from 115 to $4,200 \mu \mathrm{g} /$ g. Here, a Box-Behnken design was used to evaluate the influence of three process variables (amplitude level, ultrasonication time and temperature) on the extraction of tocols and $\gamma$-oryzanol from rice bran using ultrasound and soybean oil as a green solvent.

\subsection{Effect of UASO on tocols content of the oil extract}

Coded experiments and concentration values of each tocopherol obtained for each run of the central composite design were studied and results are given in Table 2 . Wide variations in all the responses resulted from the parameter settings of the experiment. Values ranged from 36.8 to $99.6 \mu \mathrm{g} / \mathrm{g}$ for $\alpha$-tocopherol, 121.1 to 219.5 $\mu \mathrm{g} / \mathrm{g}$ for $\gamma$-tocopherol, and 131.2 to $265.2 \mu \mathrm{g} / \mathrm{g}$ for $\delta$ tocopherol, respectively. However, concentrations of tocopherols in the extract were improved using ultrasound and soybean oil offered attractive advantages (oil solubility of vitamin E). Results indicated that all models showed significance at $99 \%$ with $95 \%$ confidence level, with lack of fit as non-significant (Table 3). Regression coefficients of responses with different terms of process variables are illustrated in Table 4. A coefficient with a positive sign at a linear level means an increase in response value with decreasing level of the variable. At interaction level, the level of one variable increased and another decreased given the same response values. In the case of tocopherols analysis, a high coefficient of determination
$\left(R^{2}\right)(0.9589$ to 0.9836$)$ with the predicted $R^{2}$ of 0.7689 to 0.8984 was in reasonable agreement with adjusted $R^{2}$ of 0.9126 to 0.9652 . In linear terms, all the variables studied were found to have significant model terms, with an increasing effect on $\alpha$-tocopherol and $\gamma$-tocopherol $(p<0.005)$ (Table 3). Similarly, ultrasonic time and temperature provided a significant model for $\delta$ tocopherol $(p<0.005$ and $p<0.05$, respectively). Quadratic effects of the amplitude level $\left(\mathrm{A}^{2}\right)$, temperature $\left(\mathrm{B}^{2}\right)$ and extraction time $\left(\mathrm{C}^{2}\right)$ on all responses showed high significance. However, no significance was determined for interactions between A and $\mathrm{C}$ for $\alpha$-tocopherol and $\gamma$-tocopherol, and between $\mathrm{A}$ and $\mathrm{B}$ for $\delta$-tocopherol.

Response surface and contour plots for $\alpha$-tocopherol in relation to temperature-amplitude level (a), timeamplitude level (b), and temperature-time are shown in Figure 2. Results indicated that for an ultrasonic treatment time of 40-60 mins at a temperature of $45-65^{\circ}$ $\mathrm{C}$, the concentration of $\alpha$-tocopherol increased by a specific amplitude percentage. Similar results to $\alpha$ tocopherol were observed for plots of the other tocopherol isomers studied $(\gamma$-tocopherol and $\delta$ tocopherol) (data not shown). These results indicated that the viscosity of soybean oil decreased with increasing extraction temperature resulting in enhanced extractability and concentration of tocols. Findings were in agreement with Goula et al. (2017) who reported that a higher extraction yield of carotenoids from pomegranate wastes was associated with a lower viscosity of vegetable oils solvents. In the extraction process of sulfur aroma compounds, a low solvent

Table 2. Experimental design for the three independent variables and observed values of response variables

\begin{tabular}{cccccccc}
\hline Run & $\begin{array}{c}\text { Amplitude } \\
\text { level }(\%)\end{array}$ & $\begin{array}{c}\text { Temperature } \\
\left({ }^{\circ} \mathrm{C}\right)\end{array}$ & $\begin{array}{c}\text { Time } \\
(\mathrm{min})\end{array}$ & $\begin{array}{c}\alpha \text {-tocopherol } \\
(\mu \mathrm{g} / \mathrm{g})\end{array}$ & $\begin{array}{c}\gamma \text {-tocopherol } \\
(\mu \mathrm{g} / \mathrm{g})\end{array}$ & $\begin{array}{c}\delta \text {-tocopherol } \\
(\mu \mathrm{g} / \mathrm{g})\end{array}$ & $\begin{array}{c}\gamma \text {-oryzanol } \\
(\mu \mathrm{g} / \mathrm{g})\end{array}$ \\
\hline 1 & 1 & 1 & -1 & 75.4 & 201.2 & 175.9 & 445.1 \\
2 & 0 & 1.682 & 0 & 83.1 & 219.5 & 235.6 & 487.7 \\
3 & -1 & -1 & 1 & 51.6 & 156.3 & 138.6 & 283.4 \\
4 & 1 & -1 & -1 & 49.6 & 136.5 & 135.2 & 257.6 \\
5 & 1 & 1 & 1 & 85.3 & 198.6 & 248.9 & 469.3 \\
6 & -1 & 1 & 1 & 74.3 & 176.5 & 178.6 & 337.2 \\
7 & 0 & 0 & 0 & 92.5 & 214.3 & 265.2 & 489.8 \\
8 & 0 & 0 & -1.682 & 48.6 & 143.5 & 131.2 & 280.6 \\
9 & 1 & -1 & 1 & 79.3 & 206.2 & 167.6 & 467.6 \\
10 & -1 & 1 & -1 & 72.2 & 188.1 & 189.5 & 411.4 \\
11 & 1.682 & 0 & 0 & 81.6 & 198.5 & 156.9 & 437.4 \\
12 & 0 & 0 & 1.682 & 82.6 & 178.4 & 166.9 & 423.1 \\
13 & 0 & 0 & 0 & 98.6 & 213.6 & 235.3 & 469.8 \\
14 & -1 & -1 & -1 & 36.8 & 121.1 & 156.3 & 245.5 \\
15 & -1.682 & 0 & 0 & 49.3 & 134.2 & 135.6 & 252.5 \\
16 & 0 & -1.682 & 0 & 43.5 & 141.1 & 149.3 & 258.5 \\
17 & 0 & 0 & 0 & 96.8 & 198.3 & 265.2 & 468 \\
18 & 0 & 0 & 0 & 99.6 & 200.8 & 255.9 & 470.1 \\
C.V. $(\%)$ & & & & 5.28 & 5.03 & 7.67 & 5.81 \\
\hline & & & & & & &
\end{tabular}



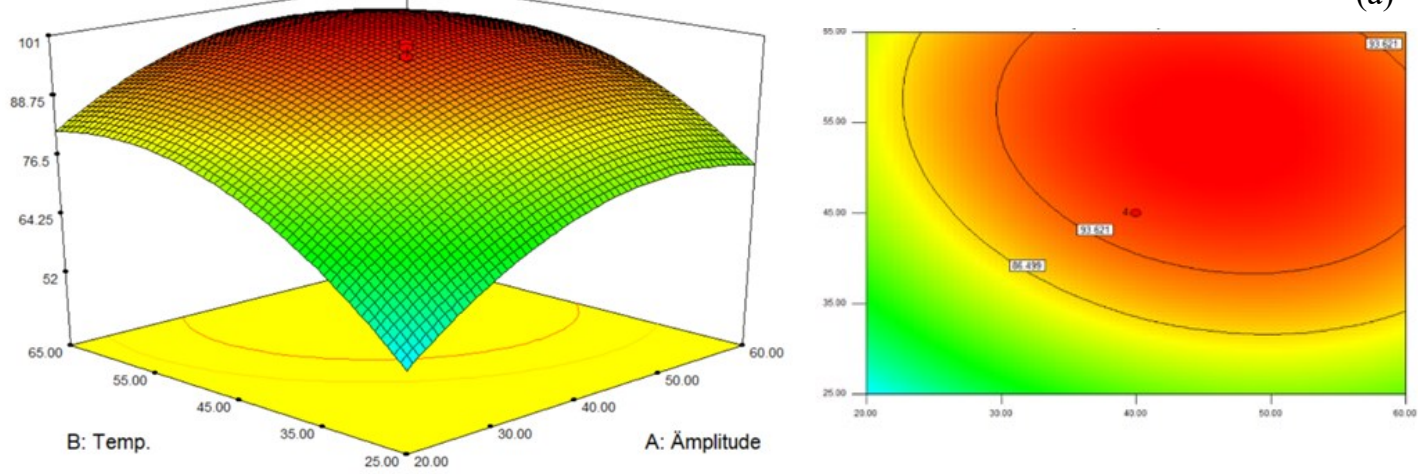

(b)
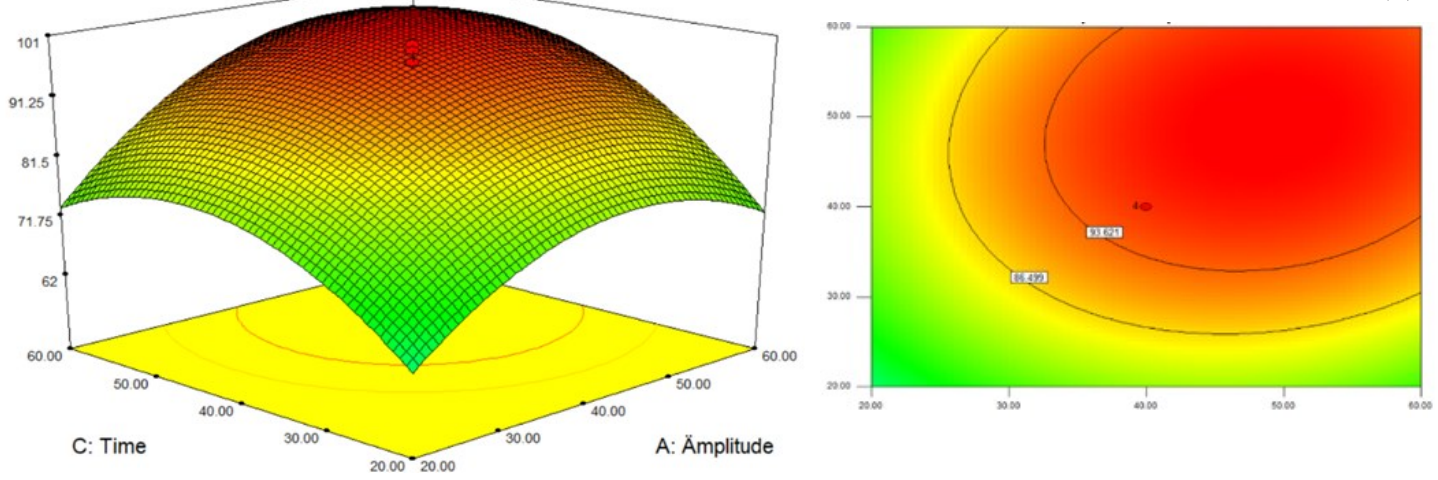

(c)
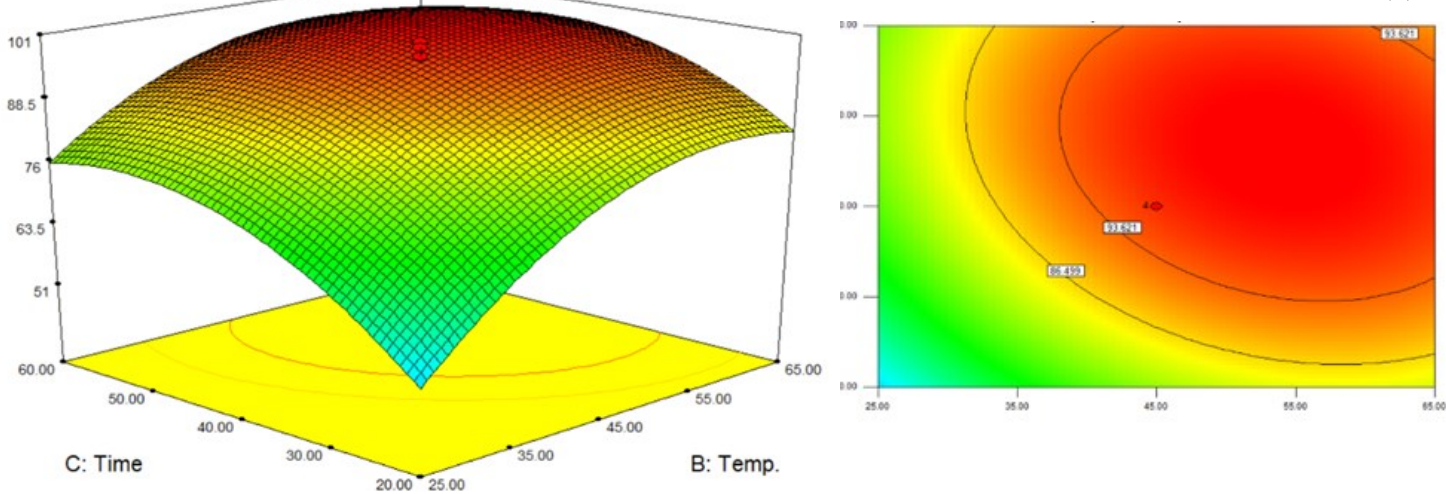

Figure 2. Response surface and contour plots for effects of independent variables (temperature -amplitude (a), time - amplitude (b) and time-temperature (c) on the concentration of $\alpha$-tocopherol from rice bran using ultrasound techniques with soybean oil as a solvent.

viscosity accelerates solvent mass transfer through the matrix and increases extraction efficiency (Pierre et al., 2002). In ultrasonic-assisted extraction of carotenoids using vegetable oils, extraction yield increased with increasing temperature from 20 to $40^{\circ} \mathrm{C}$, amplitude levels up to $40 \%$, and peel/solvent ratio of up to 0.2 (Goula et al., 2017). This phenomenon may result from the oil-soluble property of tocols and cavitation effects. When ultrasound is applied to the surface of materials, cavitation bubbles collapse and release pressure and temperature as micro-jets toward the surface of the materials (Wen et al., 2018). Simultaneously, the propagation of a strong ultrasound wave induces compression and shearing of the solvent molecules (Goula et al., 2017). As a result, rice bran cell membranes are destroyed and, consequently, intercellular substances are released into the solvent resulting in increased extraction yield. In addition, a high degree of bubble collapse produces turbulent flow conditions associated with high pressures and temperatures (Li et al., 2004). These effects lead to swelling and hydration, causing expansion of the pores in the cell wall (Ashokkumar, 2014). Similar results were reported by Pan et al. (2011), Goula et al. (2017) and Mnayer et al. (2017). However, the number of cavitation bubbles varied with the frequency of the sound wave pulse (Wen et al., 2018). The ultrasonic-assisted extraction process with high amplitude caused liquid agitation rather than cavitation (Chemat et al., 2017; Wen et al., 2018), achieving high yields of rice bran tocopherols at $40 \%$ amplitude, $40 \mathrm{mins}$ and $45^{\circ} \mathrm{C}$. Similar trends were reported by Chemat et al. (2011) who indicated that the most efficient period for industrial ultrasonic extraction was 60 mins or less. Therefore, the application of ultrasound techniques with soybean oil as a solvent showed potential for vitamin E extraction from 
rice bran.

\subsection{Effect of UASO on $\gamma$-oryzanol content of the oil extract}

In addition to rice bran tocols, $\gamma$-oryzanol is one of the most important rice bran bioactive compounds with a significant positive effect on human health. The maximum concentration of $\gamma$-oryzanol observed in the oil extract was $489.8 \mu \mathrm{g} / \mathrm{g}$ while the minimum was 245.5 $\mu \mathrm{g} / \mathrm{g}$ as shown in Table 2 . The effects of independent variables on the responses are given in Table 3. Results revealed that the model obtained was significant with lack of fit showing non-significance for $\gamma$-oryzanol. All process factors had a significant effect $(p<0.001)$ at the linear level for $\gamma$-oryzanol. The quadratic level of all the variables showed a significantly positive effect on the amplitude level $\left(\mathrm{A}^{2}\right)$, temperature $\left(\mathrm{B}^{2}\right)$ and extraction time $\left(\mathrm{C}^{2}\right)$ for $\gamma$-oryzanol at $p<0.005$. However, all interaction terms showed significance $(p<0.001)$ with either positive or negative effects for amplitude-time and temperature-time interactions on $\gamma$-oryzanol, except for the amplitude-temperature interaction term. In this study, an increase in extraction yield of $\gamma$-oryzanol was recorded as temperature increased. At an ultrasonic treatment time of 20-40 mins and the amplitude level of $20-40 \%$, the yield of $\gamma$-oryzanol increased rapidly and then decreased slightly above both these values. These variations may be due to the ultrasonic treatment which facilitated emulsion droplet break-up of soybean oil. The reaction process initially strengthened rapidly. As time and amplitude level increased, the response reversed and oil oxidation reduced due to cavitation effects during extraction and concentration of $\gamma$-oryzanol. This result was supported by Chemat et al. (2004), who reported that the application of ultrasonic oil extraction accelerated the rancid odor and changed the oil components. The cavitation phenomenon was a crucial factor affecting the quality of oils (Manickam et al., 2014). Extraction yields of peanut oil and oxidation degree were associated with the cavitation effect (Zhang et al., 2017). The oil formed a barrier against oxygen molecules resulting in retarding the oxidation time and degradation rate of the carotenoids ( $\mathrm{Pu}$ et al., 2010). In addition to the cavitation effect of ultrasound, viscosity of the oil solvent was related to the yield of the response (see discussion above). The model obtained fitted the experimental data with a correlation coefficient of 0.9745 (Table 4). Interestingly, a high yield of $\gamma$ oryzanol was observed in the extract subjected to ultrasound and soybean oil, which reached the desired level in a short extraction time (40 mins). Similar findings were obtained by previous studies; Loypimai et al. (2015) reported that sonication pretreatment significantly increased yields of oil recovery and $\gamma$ oryzanol in rice bran oil. The use of ultrasound potentially enhanced extraction yields of rice bran oil (Khoei and Chekin, 2016), resveratrol from Polygonum cuspidatum (Mantegna et al., 2012), and bioactive compounds from medicinal crops (Wen et al., 2018). Overall, optimized conditions obtained for $\gamma$-oryzanol were extraction at $40 \%$ amplitude, 40 mins and $45^{\circ} \mathrm{C}$. Extraction of $\gamma$-oryzanol using ultrasound and soybean oil as a substitute for organic solvents was successfully applied for the extraction of rice bran bioactive compounds to prepare both functional oil ingredients and foods.

\subsection{Comparison of tocols and $\gamma$-oryzanol content of $O$ - UASO and O-CSE}

Figure 3 shows the increased yield of tocopherols and $\gamma$-oryzanol in the oil extracts obtained from the optimal conditions ( $40 \%$ amplitude, 40 mins and $45^{\circ} \mathrm{C}$ )

Table 3. Analysis of variance (ANOVA) for the response variables

\begin{tabular}{|c|c|c|c|c|c|c|c|c|c|}
\hline \multirow{2}{*}{ Source } & \multirow{2}{*}{$\mathrm{df}$} & \multicolumn{2}{|c|}{$\alpha$-tocopherol } & \multicolumn{2}{|c|}{$\gamma$-tocopherol } & \multicolumn{2}{|c|}{$\delta$-tocopherol } & \multicolumn{2}{|c|}{$\gamma$-oryzanol } \\
\hline & & $\mathrm{SS}$ & $p$-value & $\mathrm{SS}$ & $p$-value & $\mathrm{SS}$ & $p$-value & $\mathrm{SS}$ & $p$-value \\
\hline Model $^{a}$ & 9 & 6993.66 & $<0.0001$ & 16745.47 & $<0.0001$ & 38843.48 & 0.0001 & 15400 & $<0.0001$ \\
\hline A & 1 & 870.32 & $<0.0001$ & 3187.44 & 0.0002 & 738.43 & 0.0965 & 33171.22 & $<0.0001$ \\
\hline $\mathrm{B}$ & 1 & 1793.38 & $<0.0001$ & 5584.03 & $<0.0001$ & 8481.49 & 0.0002 & 46205.28 & $<0.0001$ \\
\hline $\mathrm{C}$ & 1 & 946.29 & $<0.0001$ & 1634.25 & 0.002 & 1371.12 & 0.0333 & 14018.95 & 0.0008 \\
\hline $\mathrm{AB}$ & 1 & 86.46 & 0.0408 & 113.25 & 0.2717 & 297.68 & 0.2661 & 116.28 & 0.6439 \\
\hline $\mathrm{AC}$ & 1 & 64.41 & 0.0687 & 236.53 & 0.1264 & 2244.5 & 0.0111 & 9146.28 & 0.0028 \\
\hline $\mathrm{BC}$ & 1 & 132.03 & 0.0168 & 1773.1 & 0.0016 & 280.85 & 0.279 & 11093.05 & 0.0016 \\
\hline$A^{2}$ & 1 & 1399.95 & $<0.0001$ & 2123.19 & 0.0009 & 15439.71 & $<0.0001$ & 22834.29 & 0.0001 \\
\hline $\mathrm{B}^{2}$ & 1 & 1609.56 & $<0.0001$ & 814.35 & 0.0133 & 4377.55 & 0.0018 & 13389.58 & 0.0009 \\
\hline $\mathrm{C}^{2}$ & 1 & 1385.87 & $<0.0001$ & 2795.05 & 0.0004 & 14577.13 & $<0.0001$ & 20287.41 & 0.0002 \\
\hline Residual & 8 & 116.59 & & 650.09 & & 1666.09 & & 4032.72 & \\
\hline Lack of fit ${ }^{b}$ & 5 & 87.04 & 0.339 & 439.06 & 0.4556 & 1069.75 & 0.5086 & 3714.08 & 0.0701 \\
\hline Pure error & 3 & 29.55 & & 211.03 & & 596.34 & & 318.64 & \\
\hline Total & 17 & 7110.24 & & 17395.56 & & 40509.57 & & 15800 & \\
\hline
\end{tabular}

${ }^{\mathrm{a}}$ Significant, ${ }^{\mathrm{b}}$ Non-significant, A: Amplitude level (\%), B: Extraction temperature $\left({ }^{\circ} \mathrm{C}\right)$, C: Extraction time (min) 
Table 4. Regression coefficients of different responses

\begin{tabular}{ccccc}
\hline \multirow{2}{*}{ Factor } & \multicolumn{4}{c}{ Coefficients } \\
\cline { 2 - 5 } & $\alpha$-tocopherol & $\gamma$-tocopherol & $\delta$-tocopherol & $\gamma$-oryzanol \\
\hline Intercept & $96.74 * * *$ & $206.46^{* * *}$ & $254.58^{* * *}$ & $473.67 * * *$ \\
$\beta_{1}$ & $7.98^{* * *}$ & $15.28^{* * *}$ & 7.35 & $49.28^{* * *}$ \\
$\beta_{2}$ & $11.46^{* * *}$ & $20.22^{* * *}$ & $24.92^{* * *}$ & $58.17 * * *$ \\
$\beta_{3}$ & $8.32^{* * *}$ & $10.94 * * *$ & $10.02^{*}$ & $32.04 * * *$ \\
$\beta_{12}$ & $-3.29 *$ & -3.76 & 6.1 & -3.81 \\
$\beta_{13}$ & 2.84 & 5.44 & $16.75^{*}$ & $33.81 * *$ \\
$\beta_{23}$ & $-4.06^{*}$ & $-14.89 *$ & 5.93 & $-37.24 * * *$ \\
$\beta_{11}$ & $-10.52^{* * *}$ & $-12.96 * * *$ & $-34.94 * * *$ & $-42.49 * * *$ \\
$\beta_{22}$ & $-11.28^{* * *}$ & $-8.02 *$ & $-18.60^{* * *}$ & $-32.54 * * *$ \\
$\beta_{33}$ & $-10.47 * * *$ & $-14.86^{* * *}$ & $-33.95 * * *$ & $-40.05 * * *$ \\
\hline $\mathrm{R}^{2}$ & 0.9836 & 0.9626 & 0.9589 & 0.9745 \\
Adjusted $\mathrm{R}^{2}$ & 0.9652 & 0.9206 & 0.9126 & 0.9458 \\
Predicted $\mathrm{R}^{2}$ & 0.8984 & 0.7797 & 0.7689 & 0.8113 \\
Adeq precision & 22.685 & 15.896 & 12.272 & 16.671 \\
PRESS & 722.52 & 3832.42 & 9362.59 & 29819.32 \\
\hline
\end{tabular}

A: Amplitude level (\%), B: Extraction temperature $\left({ }^{\circ} \mathrm{C}\right), \mathrm{C}$ : Extraction time (min). $* * * p<0.005, * * p<0.01, * p<0.05$
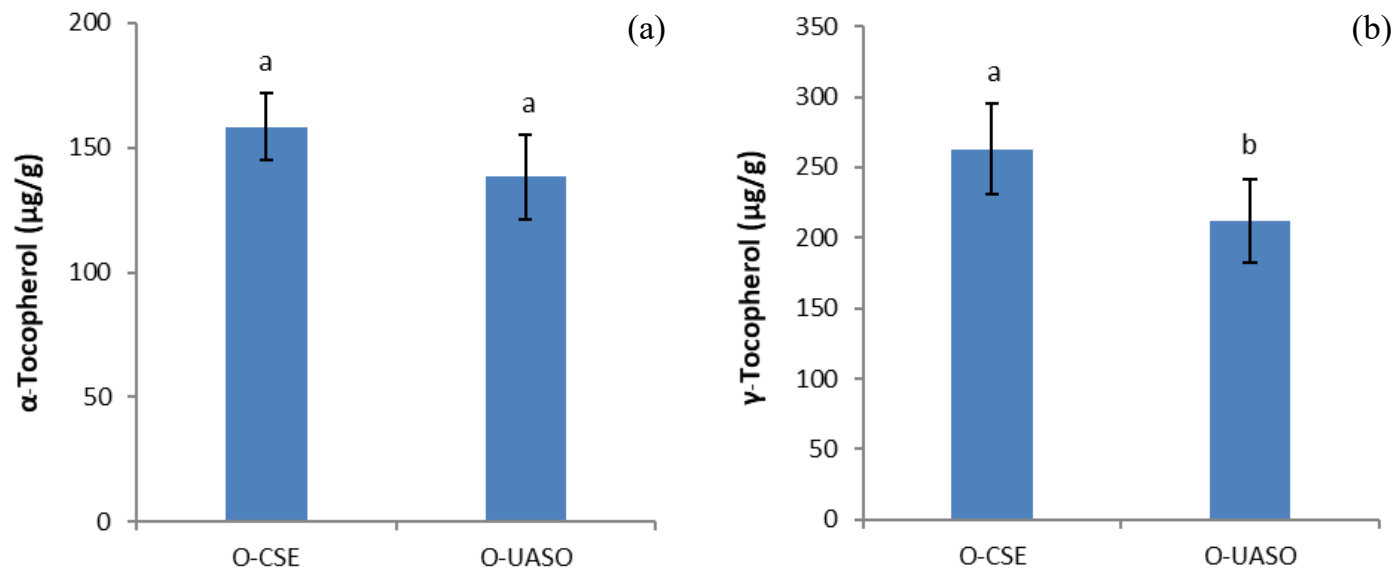

(b)

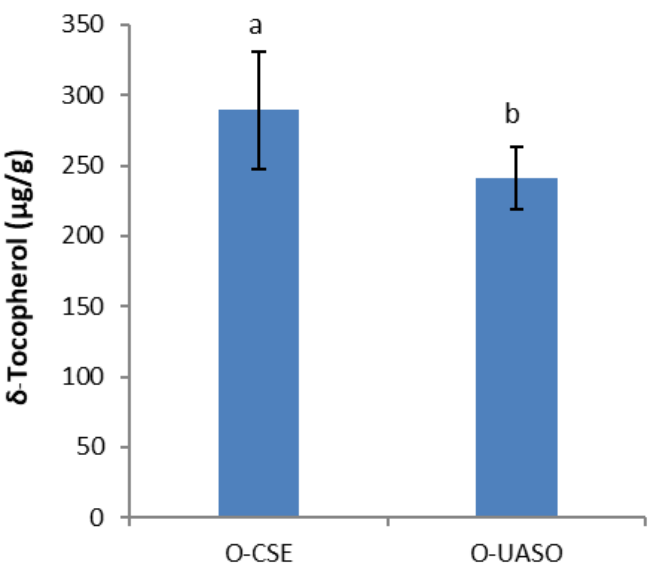

(c)

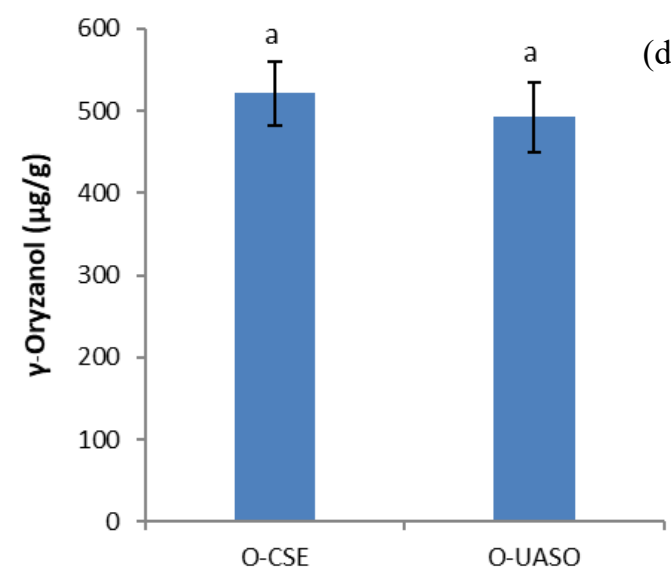

Figure 3. Increased tocopherols and $\gamma$-oryzanol concentration in oils produced by the optimal conditions of ultrasound-assisted soybean oil extraction (O-UASO) and conventional solvent extraction (O-CSE). Each observation is mean $\pm \mathrm{SD}$ of triplicate experiments. Different letters above columns indicate a significant difference $(p<0.05)$. Vertical bars on each column indicate standard deviation.

of O-UASO and O-CSE. Significant differences in $\gamma$ tocopherol, and $\delta$-tocopherol were observed between the extraction processes $(p<0.05)$. The O-CSE extraction method contained a higher concentration of $\gamma$-tocopherol $(262.98 \pm 32.11 \mu \mathrm{g} / \mathrm{g})$, and $\delta$-tocopherol $(289.23 \pm 41.32$ $\mu \mathrm{g} / \mathrm{g})$ than O-UASO. Interestingly, the concentration of both $\alpha$-tocopherol and $\gamma$-oryzanol by O-UASO was close to O-CSE. This result may be due to shearing and crushing of rice bran particles and cell membranes caused by cavitation and mechanical effects. Ultrasound waves enhanced the contact surface area between the active compounds and liquid surfaces, improved 
penetration of the oil solvent into the bran matrix, and increased solubility of lipophilic substances. This is one of the main reasons for obtaining high yields of tocols and $\gamma$-oryzanol by O-UASO, compared to oil extracted by organic solvents. This result concurred with Khoei and Chekin (2016) who reported that yield of rice bran oil using ultrasound-assisted aqueous extraction was comparable to yield by hexane Soxhlet extraction, while the oil obtained had lower free fatty acid content. Yi et al. (2020) reported on the extraction of $\gamma$-oryzanol from heated rice bran using corn oil as a solvent and the increase in oxidative stability of corn oils containing high rice bran $\gamma$-oryzanol. The edible oil acted as a barrier that protected against the attraction of oxygen molecules and, consequently, retarded oxidation and degradation rates of the carotenoid extract $(\mathrm{Pu}$ et al., 2010). In addition, application of ultrasound with soybean oil offered many advantages including reduction of solvent, time and energy consumption for extraction.

\subsection{Comparison of the antioxidant activity of O-UASO and $O-C S E$}

Antioxidant activities of oil extracts obtained from different extraction processes and commercial soybean oil (solvent) were evaluated using three established methods including DPPH radical scavenging ( $\left.\mathrm{IC}_{50}\right)$, ferric reducing/antioxidant power (FRAP), and total antioxidant capacity (TAC). Results are displayed in Table 5. Among the antioxidant activity assays, lower IC50 and higher FRAP values were found in O-UASO and O-CSE than in soybean oil. Interestingly, O-UASO showed significantly $(p<0.05)$ highest TAC $(2.69 \pm 0.03$ $\mathrm{mg}$ GAE/g oil), followed by O-CSE $(0.72 \pm 0.09 \mathrm{mg}$ $\mathrm{GAE} / \mathrm{g}$ oil) and soybean oil $(0.11 \pm 0.04 \mathrm{mg} \mathrm{GAE} / \mathrm{g}$ oil $)$, respectively. These effects also related to the concentration of tocopherols and $\gamma$-oryzanol in the oil extract that had antioxidant properties. This finding concurred with previous studies (Loypimai et al., 2015; Loypimai et al., 2016). They reported that black rice bran colorant power containing higher tocopherols, tocotrienols, and $\gamma$-oryzanol showed stronger antioxidant activity. Yi et al. (2020) reported that antioxidant capacities of corn oils were increased by solvating $\gamma$ oryzanol from rice bran. Godber and Wells (1994) mentioned that rice bran is considered a potentially valuable source of natural antioxidants such as tocopherols, tocotrienols and oryzanol. These compounds are the major antioxidants present in rice bran, with oryzanols having 10 times higher antioxidant activity than tocopherols, while tocotrienols have 40-60 times greater antioxidant power compared to tocopherols. According to this study above, compared with O-CSE, the O-UASO method gave lower concentrations of $\gamma$-tocopherol, and $\delta$-tocopherol, while
O-UASO showed high TAC. This was because antioxidant capacities of the O-UASO method were increased by other lipophilic antioxidant compounds from rice bran such as phenolic acids and carotenoids, whereas thermally sensitive compounds were degraded during the conventional solvent extraction process.

Table 5. Antioxidant activities of oil obtained from the optimal conditions of ultrasound-assisted soybean oil extraction $(\mathrm{O}-$ UASO), conventional solvent extraction (O-CSE), and soybean oil (solvent) evaluated by three different chemical assays

\begin{tabular}{cccc}
\hline $\begin{array}{c}\text { Extraction } \\
\text { process }\end{array}$ & DPPH & FRAP & $\begin{array}{c}\text { Total } \\
\text { antioxidant } \\
\text { capacity }\end{array}$ \\
\hline O-CSE & $124.3 \pm 15.6^{\mathrm{b}}$ & $59.6 \pm 9.1^{\mathrm{a}}$ & $0.72 \pm 0.09^{\mathrm{b}}$ \\
O-UASO & $215.6 \pm 11.2^{\mathrm{b}}$ & $53.3 \pm 6.3^{\mathrm{a}}$ & $2.69 \pm 0.03^{\mathrm{a}}$ \\
Soybean oil & $395.7 \pm 13.4^{\mathrm{a}}$ & $12.1 \pm 8.2^{\mathrm{b}}$ & $0.11 \pm 0.04^{\mathrm{c}}$ \\
\hline
\end{tabular}

Values are means \pm SD of triplicate samples. Values with the same letter within columns are not significantly different $(\mathrm{p}<0.05)$.

DPPH was expressed as $\mathrm{IC}_{50}, \mathrm{mg} / \mathrm{g}$ : Concentration of the amount of the extract to inhibit $50 \%$ of stable free. DPPH radical; FRAP: Ferric reducing antioxidant power; GAE: Gallic acid equivalent.

\section{Conclusion}

Our results demonstrated that response surface methodology was successfully applied to investigate the optimization of processing conditions (amplitude level (A) of $20-60 \%$, temperature (B) of $25-65^{\circ} \mathrm{C}$ and process duration (C) of 20-60 mins) for ultrasound extraction with soybean oil as a natural solvent of tocopherols and $\gamma$ -oryzanol from rice bran. The statistical analysis clearly showed that data obtained in this experimental study fitted to the models developed for predicting the extraction yield of tocopherols and $\gamma$-oryzanol $\left(\mathrm{R}^{2}>0.77\right)$. Overall, optimal process conditions obtaining maximum concentrations of tocopherols and $\gamma$-oryzanol were $40 \%$ amplitude level, $45^{\circ} \mathrm{C}$ solution temperature and 40 mins. Yields of $\alpha$-tocopherol and $\gamma$-oryzanol by O-UASO under optimal conditions $\left(40 \%\right.$ amplitude level, $45^{\circ} \mathrm{C}$ solution temperature and 40 mins) were similar to yields by O-CSE. Interestingly, the O-UASO method showed higher TAC than O-CSE and commercial soybean oil. Results suggested that extraction using ultrasound with soybean oil could be used as an alternative process to improve the functionality of edible vegetable oils and produce vegetable oils containing high bioactive substances without the necessity of separating environmentally hazardous organic solvents. 


\section{Conflict of interest}

The authors declare no conflict of interest.

\section{Acknowledgments}

The authors are grateful for financial and laboratory support received from the Research and Development Institute (Year, 2561), Bansomdejchaopraya Rajabhat University, and Mahasarakham University, Thailand.

\section{References}

Ashokkumar, C.R. (2014). Vibration control for structural damage mitigation. Journal of Vibration and Control, 211(5), 2995-3006. https:// doi.org/10.1177/1077546313519283

Balachandran, C., Mayamol, P.N., Thormas, S., Sukumar, D., Sundaresan, A. and Arumughan, C. (2008). An ecofriendly approach to process rice bran for high quality rice bran oil using supercritical carbon dioxide for nutraceutical applications. Bioresource Technology, 99(8), 2905-2912. https:// doi.org/10.1016/j.biortech.2007.06.004

Benzie, I.F. and Strain, J.J. (1996). The ferric reducing ability of plasma (FRAP) as a measure of "antioxidant power": the FRAP assay. Analytical Biochemistry, 239(1), 70-76. https://doi.org/10.1006/ abio.1996.0292

Chemat, F., Grondin, I., Costes, P., Moutoussamy, L., Sing, A.S.C. and Smadja, J. (2004). High power ultrasound effects on lipid oxidation of refined sunflower oil. Ultrasonics Sonochemistry, 11(5), 281 -285. https://doi.org/10.1016/j.ultsonch.2003.07.004

Chemat, F., Huma, Z. and Khan, M.K. (2011). Applications of ultrasound in food technology: Processing, preservation and extraction. Ultrasonics Sonochemistry, 18(4), 813-835. https:// doi.org/10.1016/j.ultsonch.2010.11.023

Chemat, F., Rombaut, N., Sicaire, A.-G., Meullemiestre, A., Fabiano-Tixier, A. and Abert-Vian, M. (2017). Ultrasound assisted extraction of food and natural products. Mechanisms, Techniques, combinations, protocols and applications-A review. Ultrasonics Sonochemistry, 34, 540-560. doi.org/510.1016/ j.ultsonch.2016.1006.1035.

Chemat, F., Vian, M.A. and Cravotto, G. (2012). Green extraction of natural products: concept and principles. International Journal of Molecular Sciences, 13(7), 8615-8627. https://doi.org/10.3390/ ijms13078615

Chen, M., Zhao, Y. and Yu, S. (2015). Optimisation of ultrasonic-assisted extraction of phenolic compounds, antioxidants, and anthocyanins from sugar beet molasses. Food Chemistry, 172, 543-550. https://doi.org/10.1016/j.foodchem.2014.09.110

Dasgupta, N. and De, B. (2004). Antioxidant activity of Piper betle L. leaf extract in vitro. Food Chemistry, 88(2), 219-224. https://doi.org/10.1016/ j.foodchem.2004.01.036

FAO (Food and Agriculture Organization). (2016). Statistical database. Retrieved on August 24, 2016 from FAO Stat website: http://faostat3.fao.org/home/ E.

Godber, J.S. and Well, J.H. (1994). Rice bran: as a viable source of high value chemicals. Louisiana Agriculture, 37(2), 13-17.

Goula, A.M., Ververi, M., Adamopoulou, A. and Kaderides, K. (2017). Green ultrasound-assisted extraction of carotenoids from pomegranate wastes using vegetable oils. Ultrasonics Sonochemistry, 34, 821-830.

https://doi.org/10.1016/ j.ultsonch.2016.07.022

Grilo, E.C., Costa, P.N., Gurgel, C.S.S., Beserra, A.F.L., Almeida, F.N.S. and Dimenstein, R. (2014). Alphatocopherol and gamma-tocopherol concentration in vegetable oils. Food Science and Technology, 34(2), 379-385.

Khoei, M. and Chekin, F. (2016). The ultrasoundassisted aqueous extraction of rice bran oil. Food Chemistry, 194, 503-507. https://doi.org/10.1016/ j.foodchem.2015.08.068

Li, H., Pordesimo, L. and Weiss, J. (2004). High intensity ultrasound-assisted extraction of oil from soybeans. Food Research International, 37(7), 731738. https://doi.org/10.1016/j.foodres.2004.02.016

Loypimai, P., Moongngarm, A. and Chottanom, P. (2009). Effects of ohmic heating on lipase activity, bioactive compounds and antioxidant activity of rice bran. Australian Journal of Basic and Applied Sciences, 3(4), 3642-3652.

Loypimai, P., Moongngarm, A. and Chottanom, P. (2015). Impact of stabilization and extraction methods on chemical quality and bioactive compounds of rice bran oil. Emirates Journal of Food and Agriculture, 27(11), 849-856. https:// doi.org/10.9755/ejfa.2015-09-738

Loypimai, P., Moongngarm, A. and Chottanom, P. (2016). Phytochemicals and antioxidant capacity of natural food colorant prepared from black waxy rice bran. Food Bioscience, 15, 34-41. https:// doi.org/10.1016/j.fbio.2016.04.003

Manickam, S., Abidin, N.Z., Parthasarathy, S., Alzorqi, I., Ng, E.H., Tiong, T.J., Gomes, R.L. and Ali, A. (2014). Role of $\mathrm{H} 2 \mathrm{O} 2$ in the fluctuating patterns of COD (chemical oxygen demand) during the 
treatment of palm oil mill effluent (POME) using pilot scale triple frequency ultrasound cavitation reactor. Ultrasonics Sonochemistry, 21(4), 15191526. https://doi.org/10.1016/j.ultsonch.2014.01.002

Mantegna, S., Binello, A., Boffa, L., Giorgis, M., Cena, C. and Cravotto, G. (2012). A one-pot ultrasoundassisted water extraction/cyclodextrin encapsulation of resveratrol from Polygonum cuspidatum. Food Chemistry, 130(3), 746-750. https://doi.org/10.1016/ j.foodchem.2011.07.038

Mnayer, D., Fabiano-Tixier, A.-S., Petitcolas, E., Ruiz, K., Hamieh, T. and Chemat, F. (2017). Extraction of green absolute from thyme using ultrasound and sunflower oil. Resource-Efficient Technologies, 3(1), 12-21. https://doi.org/10.1016/j.reffit.2017.01.007

Pan, Z., Qu, W., Ma, H., Atungulu, G.G. and McHugh, T.H. (2011). Continuous and pulsed ultrasoundassisted extractions of antioxidants from pomegranate peel. Ultrasonics Sonochemistry, 18(5), 1249-1257.

https://doi.org/10.1016/ j.ultsonch.2011.01.005

Pierre, F.-X., Souchon, I., Athes-Dutour, V. and Marin, M. (2002). Membrane-based solvent extraction of sulfur aroma compounds: influence of operating conditions on mass transfer coefficients in a hollow fiber contactor. Desalination, 148(1-3), 199-204. https://doi.org/10.1016/S0011-9164(02)00698-7

$\mathrm{Pu}$, J., Bechtel, P.J. and Sathivel, S. (2010). Extraction of shrimp astaxanthin with flaxseed oil: Effects on lipid oxidation and astaxanthin degradation rates. Biosystems Engineering, 107(4), 364-371. https:// doi.org/10.1016/j.biosystemseng.2010.10.001

Virot, M., Tomao, V., Bourvellec, C.L., Renard, C.M.C.G. and Chemat, F. (2010). Towards the industrial production of antioxidants from food processing by-products with ultrasound-assisted extraction. Ultrasonics Sonochemistry, 17(6), 10661074. https://doi.org/10.1016/j.ultsonch.2009.10.015

Wen, C., Zhang, J., Zhang, H., Dzah, C. S., Zandile, M., Duan, Y., Ma, H. and Luo, X. (2018). Advances in ultrasound assisted extraction of bioactive compounds from cash crops - A review. Ultrasonics Sonochemistry, 48, 538-549. https://doi.org/10.1016/ j.ultsonch.2018.07.018

Yi, B-R., Lee, J-H. and Kim, M-J. (2020). Increasing oxidative stability in corn oils through extraction of $\gamma$ -oryzanol from heat treated rice bran. Journal of Cereal Science, 91, 102880. https://doi.org/10.1016/ j.jcs.2019.102880

Zhang, L., Zhou, C., Wang, B., Yagoub, A. E.-G. A., Ma, H., Zhang, X. and Wu, M. (2017). Study of ultrasonic cavitation during extraction of the peanut oil at varying frequencies. Ultrasonics Sonochemistry, 37, 106-113. https://doi.org/10.1016/ j.ultsonch.2016.12.034

Zhang, X., Shen, Y., Prinyawiwatkul, W., King, J.M. and $\mathrm{Xu}, \mathrm{Z}$. (2013). Comparison of the activities of hydrophilic anthocyanins and lipophilic tocols in black rice bran against lipid oxidation. Food Chemistry, 141(1), 111-116. https://doi.org/10.1016/ j.foodchem.2013.03.034 